$$
\text { POETER/L, }
$$

DOE/ER/45372--5

DE93 003121

\title{
ENERGETICS, BONDING MECHANISM AND ELECTRONIC STRUCTURE OF METAL/CERAMIC INTERFACES
}

An Annual Progress Report for

DOE Grant No. DE-FG02-88ER45372

\author{
Submitted to the \\ U.S. DEPARTMENT OF ENERGY
}

by

A. J. Freeman

Department of Physics and Astronomy

Northwestern University

Evanston, IL 60208

Period of Performance: April 1, 1992 to March 31, 1993

This report was prepared as an account of work sponsored by the United States Government. Neither the United States nor th: Department of Energy, nor any of their employees, nor any of their contractors, subcontractors, or their employees, makes any warranty, express or implied, or assumes any legal liability or responsibility for the accuracy, completeness, or usefulness of any information, apparatus, product or process disclosed or represents that its use would not infringe privately-owned rights. 


\section{TABLE OF CONTENTS}

PAGE

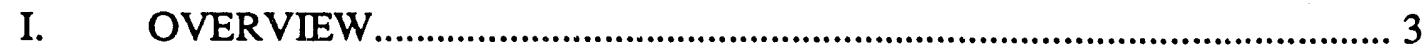

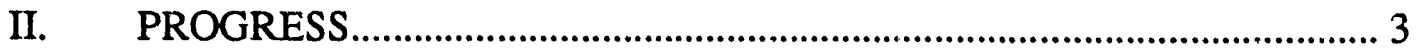

A. Electronic Structure of Noble-metal Oxides: PdO, PtO and AgO................. 3

B. Ab initio calculations of the electronic structure of the $\mathrm{TiO}_{2}(110)$

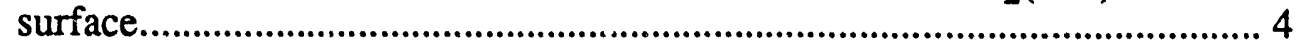

C. Electronic Structure of $\mathrm{VO}_{2}$ and $\mathrm{TiO}_{2}$ Thin Films and Multilayers............ 5

PUBLICATIONS SUPPORTED BY THE DOE (1990-PRESENT),........................ 7 


\section{OVERVIEW}

We have made good progress on several problems in the last eight months since submitting the previous continuation proposal. Several noble metal oxides PdO, PtO and AgO have been stıdied as a direct link to our earlier work on the $\mathrm{Pd} / \mathrm{A} / / \mathrm{O}_{3}$ interface. Further, as described last year, as a result of close collaborations with Dan Lam and colleagues at MSD/ANL, much of our emphasis has shifted to study oxide materials based on titanium and vanadium oxides, which are among the most important of the oxide materials currently used for technological applications. They are also, perhaps the most intriguing. As with our collaboration with Merkle of ANL and Seidman of NU, the close experimental/theoretical collaboration with Lam et al. on DOE sponsored research has been a driving engine for most of our work.

\section{PROGRESS}

A. Electronic structure of noble-metal oxides: PdO, PtO and AgO

While the $3 \mathrm{~d}$ metal oxides, $\mathrm{CoO}, \mathrm{NiO}, \mathrm{CuO}$, etc., and $\mathrm{Cu}-\mathrm{O}$ based high $\mathrm{T}_{\mathrm{c}}$ materials have been extensively studied both theoretically and experimentally, the electronic structures of noble metal oxides, such as $\mathrm{PdO}, \mathrm{PtO}$ and $\mathrm{AgO}$, are not well known. According to local density electronic band structure calculations of the $3 \mathrm{~d}$ oxides, the band gaps are either non-existent or much smaller than experimentally observed. It is well known that this discrepancy is due to the inadequate description of electron correlation by the local density approximation (LDA) for these systems. However, it is not certain that $4 \mathrm{~d}$ or $5 \mathrm{~d}$ metal oxides are categorized as strongly correlated systems like the $3 \mathrm{~d}$ oxides, since $4 \mathrm{~d}$ or $5 \mathrm{~d}$ atomic orbitals are much broader than $3 \mathrm{~d}$ orbitals and they do not represent magnetic behaviors.

We have performed band structure calculations for $\mathrm{PdO}, \mathrm{PtO}$ and $\mathrm{AgO}$ using the local density FLAPW method. The calculated band structures show that Pd and Pt atoms are strongly hybridized with oxygen atoms in comparison with $3 \mathrm{~d}$ oxides and that their oxides show metallic behaviors. The tetragonal field splitting of $d$ levels is not sufficient to obtain a gap. However, the calculated DOS are well matched with the peaks of XPS or UPS experiments. Even though 
LDA calculations do not give band gaps in $\mathrm{PdO}$ and $\mathrm{PtO}$, their band gaps are of the band type induced by the crystal field, rather than the Mott-Hubbard type or charge transfer type like the $3 \mathrm{~d}$ oxides. In $\mathrm{AgO}$, the monoclinic crystal field splitting of the $\mathrm{d}$ states induces a small indirect band gap of $0.03 \mathrm{eV}$. This splitting leads to valences of $\mathrm{Ag}$ that have $\mathrm{Ag}^{+1}$ and $\mathrm{Ag}^{+2}$ configurations rather than $\mathrm{Ag}^{+1}$ and $\mathrm{Ag}^{+3}$, since the small $\mathrm{p}$ - $\mathrm{d}$ energy separation prefers the existence of oxygen holes.

B. Ab initio calculations of the electronic structure of the $\mathrm{TiO}_{2}(110)$ surface

At present, two different cases of the clean $\mathrm{TiO}_{2}(110)$ surface are under study, namely the surface containing a mixture of $\mathrm{Ti}$ and $\mathrm{O}$ atoms, and the surface with $\mathrm{O}$ atoms only. (These cases are of interest for the chemisorption of $\mathrm{H}_{2} \mathrm{O}$ which will be studied as the next step.) The second type of surface is the experimentally stable case for the free clean surface. In both cases we try to find the minimum of the total energy as a function of the $O$ position above the ideal surface plane. These calculations of the clean surfaces took longer than expected because the charge density and, especially, the total energy converge very slowly. We are presently just finishing the relaxation of the top atoms of the $\mathrm{TiO}_{2}(110)$ surface. We found that the five-fold $\mathrm{Ti}$ is pulled inwards by $0.34 \mathrm{a} .1$, the in-plane oxygens are pulled down by 0.2 a.u and also move in the xy-plane. The 6 fold $\mathrm{Ti}$ is puiled down by 0.05 a.u. The top oxygen which sticks out from the surface is pulled down by 0.24 a.u. All these are with respect to the bulk distances. The $\mathrm{Ti}(6)-\mathrm{O}$ bond distance, as given in our first paper ("Atomistic study of the clean and hydroxylated $\mathrm{TiO}_{2}$ surface", Mat. Res. Soc. Symp. Proc. Vol. 252, 1992 MRS, p. 43-48), is practically the same although in this study we only relaxed the top $O$. In the meantime, we are working on the self-consistency problem and we hope to be able to reduce the number of selfconsistent iterations for the next problems considerably. 
C. Electronic structure of $\mathrm{VO}_{2}$ and $\mathrm{TiO}_{2}$ thin films and multilayers

We have completed the first phase of our work on the $\mathrm{VO}_{2}$ and $\mathrm{TiO}_{2}$ thin films and multilayers in collaboration with Dan Lam at Argonne National Laboratory. Electronic structure calculations using the state-of-the-art full potential LMTO method for $\mathrm{VO}_{2}$ and $\mathrm{TiO}_{2}$ bulk crystals, their surfaces and $\mathrm{VO}_{2} / \mathrm{TiO}_{2}$ superlattices have been carried out by the full-potential LMTO method and compared with experimental results obtained recently by Lam, et al., on epitaxial films. Although the nature of surface states for $\mathrm{TiO}_{2}$ and $\mathrm{VO}_{2}$ appear to be very different, in the multilayered structures a common $\mathrm{VO}_{2}-\mathrm{TiO}_{2}$ conduction band was readily formed and the distinction between "insulating" $\mathrm{TiO}_{2}$ and "metallic" $\mathrm{VO}_{2}$ layers was almost lost in very thin multilayered structures. Vanadium clectrons are essentially delocalized into the $\mathrm{TiO}_{2}$ lizyers and the electronic charge distributions in the $\mathrm{VO}_{2} / \mathrm{TiO}_{2}$ superlattice are similar to those in the usual $\mathrm{VO}_{2}$ rutile lattice. The results obtained gave some insight into the experimental data obtained by MOCVD for epitaxially grown $\mathrm{VO}_{2} / \mathrm{TiO}_{2}$ multilayers by Lam, et al.

In the work in progress, we go beyond these first calculations on the $\mathrm{TiO}_{2} / \mathrm{VO}_{2}$ multilayer by studying the real structure observed by Lam, et al., namely the (110) face of the multilayer structure system. The bulk crystals are well matched in their lattice constants on the face. In these calculations, we model the system with five layers each of the $\mathrm{VO}_{2}$ and the $\mathrm{TiO}_{2}$. This is a more severe computational problem because of the large number of atoms to be considered (36 atoms +46 empty spheres) and non-equivalent atoms (20 inequivalent atoms and 28 inequivalent $\mathrm{empty}$ spheres) that must be treated in the self-consistent solution of the local density Kohn Sham equations. This will also provide a more realistic description of the free surfaces of $\mathrm{VO}_{2}(110)$ and $\mathrm{TiO}_{2}(110)$ treated as thin films and give a more realistic description of the bulk properties of the constituents of the inultilayer - and thus make the interface results more representative of the experimental situation. Differential charge density maps to be obtained will allow us to get information about the changes of chemical bonding at the interface. As in the earlier model calculations, we will be able to determine the electrical 
conduction properties of the films and the multilayer. A detailed analysis of the total and partial densities of states as well as the energy band structure are expected to give good insight into the difference in conducting properties of the systems and to highlight the changes in electronic properties induced from the conducting part of the multilayer structure $\left(\mathrm{VO}_{2}\right)$ on the insulating region $\left(\mathrm{TiO}_{2}\right)$ and vice versa. Moreoever, we will be able to compare our previous results $\left(\mathrm{VO}_{2} / \mathrm{TiO}_{2}\right.$ matched on the $(100)$ face) in order to try to describe the nature of structure instabilities in that case. 


\section{A.J. Freeman \\ Publications Supported by the \\ U.S. DEPARTMENT OF ENERGY (DE-FG02-88ER4\$372) \\ 1990-present}

\section{Publications}

"Energetics, Bonding Mechanism and Electronic Structure of Metal/Ceramic Interfaces", (with Chun Li and C.L. Fu), Proc. Acta/Script Conf., Santa Barbara, CA, Jan. 1989, Metal-Ceramic Interfaces, eds. M. Rühle, A.G. Evans, M.F. Ashby, and J.P. Hirth, Pergamon Press (1990) p. 2.

"Structural, Electronic, and Magnetic Properties of Thin Films and Superlattices", (with A. Continenza and Chun Li), MRS Bull. Vol. XV.9, (1990) p. 27.

"Structural, Electronic, and Magnetic Properties of Interfaces", (with A. Continenza and Chun Li), to appear in Atomic-Level Properties of Isterface Materials, ed. by D. Wolf and S. Yip, Chapman and Hall, Press, London, lst ed. 1991).

"Giant Monolayer Magnetization of Fe on MgO: A Nearly Ideal 2D Magnetic System", (with Chun Li), Phys. Rev. B 43, 780 (1991).

"Computational/Theoretical Approach to the Design of New Materials", (with S.P. Tang, A. Continenza, and C. Li), in Computer Aided Innovation of New Materials, M. Doyama, T. Suzuki, J. Kihara and R. Yamamoto, eds., (Elsevier Sci. publ. B.V., North-Holland, 1991), p. 143-153.

"Energetics, Bonding Mechanism and Electronic Structure of Metal/Ceramic Interfaces: $\mathrm{Ag} / \mathrm{MgO}(001)$ )", (with Chun Li and C.L. Fu), Acta Scripta Cone., Santa Barbara, CA, Jan. 16-18, 1989; in Metal-Ceramic Interfaces, Proceedings of an International Workshop, eds. M. Rühle, A.G. Evans, M.F. Ashby, J.P. Hirth, Pergamon Press (1990), p. 2.

"Atomistic Study of the Clean and Hydroxylated $\mathrm{TiO}_{2}$ Surface", (with R. Podloucky and S.G. Steinemann), Mat. Res. Soc. Symp. Proc., 252 (1992) 43-48.

"Electronic Structure of the $\mathrm{Pd} / \mathrm{Al}_{2} \mathrm{O}_{3}$ Interface", (with K.T. Park) (in final preparation).

"Electronic Structure and Magnetic Properties of Metal/Ceramic Interface: $\mathrm{Co} / \mathrm{MgO}(001) "$, (with Chun $\mathrm{Li}$ ), (in process).

"Electronic Structure of $\mathrm{VO}_{2}$ and $\mathrm{TiO}_{2}$ Thin Films and Multilayers", (with V.A. Gubanov, D.L. Novikov and D.J. Lam), Phys. Rev. B (submitted).

"Electronic Structure, Frozen Phonons and Origin of the Ferroelectricity Instability in $\mathrm{PbTiO}_{3}$, (with K.T. Park and G.W. Li) (in final preparation).

"Electronic Structure of Noble-metal Oxides: PdO, PtO and AgO", (with K.T. Park and D.L. Novikov) (in final preparation). 


\section{Book Chapter}

"Structural, Electronic and Magnetic Properties of Thin Films and Superlattices", (with A. Continenza and Chun Li), in Atomic-Level Properties of Interface Materials, S. Yip and D. Wolf, eds., (Chapman and Hall, London, 1992).

\section{Presentations}

"Electronic Structure and Magnetism of Metal Surfaces, Overlayers and Iriterfaces", (with Chun Li and R.Q. Wu), Proc. NATO Summer School, Greece, June 1990.

"Structural, Electronic and Magnetic Properties of Metal/Ceramic Interfaces: Fe/MgO(001)" (with Chun), paper presented at the March 1990 APS Mtg., Anaheim, CA.

"Computational/Theoretical Approach to the Design of New Materials", (with S.P. Tang, A. Continenza, and C. Li), invited paper for Proc. Intl. Conf. on Computer Applications to Matls. Sci. \& Engr., Tokyo, Japan, Aug. 28-31, 1990.

"Atomistic Study of the Clean and Hydroxylated $\mathrm{TiO}_{2}$ Surface", (with R. Podloucky and S.G. Steinemann), Fall Matls. Res. Soc. Mtg., Boston, MA, Dec. 2-6, 1991.

"Electronic Structure, Frozen Phonons and Origin of the Ferroelectricity Instability in $\mathrm{PbTiO}_{3}$ ", (with Guangwei Li and Key Taeck Park), paper presented at APS Mtg., Indianapolis, IN, March 16-22, 1992.

"Electronic Structure of Thin Films and Multilayers of $\mathrm{TiO}_{2}$ and $\mathrm{VO}_{2}$ " (with D.L. Novikov and V.A. Gubanov), paper presented at APS Mtg., Indianapolis, IN, March 16-22, 1992. 

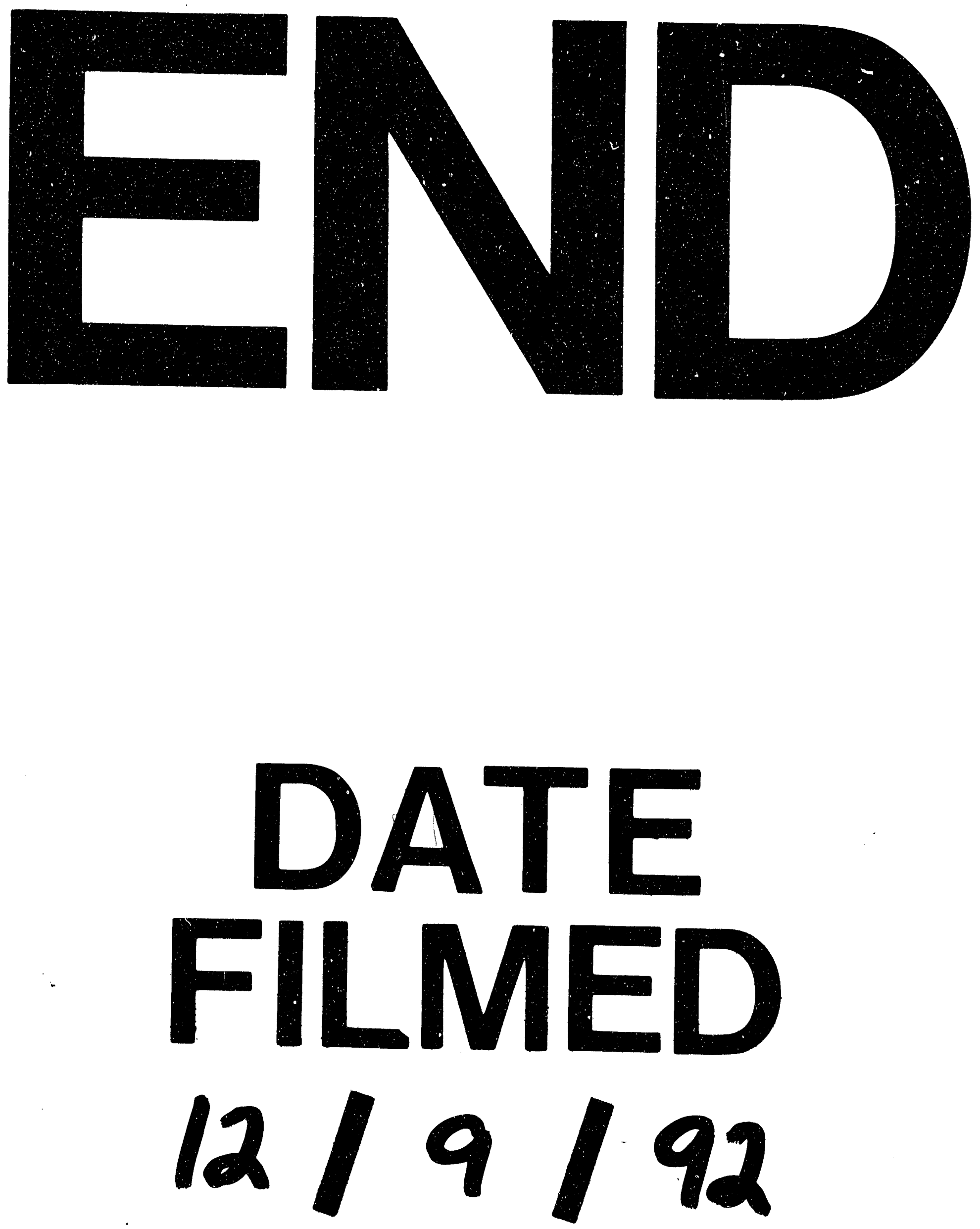
